\title{
Multi-port isolated LLC resonant converter for distributed energy generation with energy storage
}

Tomas Manez, Kevin; Zhang, Zhe; Ouyang, Ziwei

Published in:

Proceedings of 2017 IEEE Energy Conversion Congress and Exposition (ECCE)

Link to article, DOI:

10.1109/ECCE.2017.8096434

Publication date:

2017

Document Version

Peer reviewed version

Link back to DTU Orbit

Citation (APA):

Tomas Manez, K., Zhang, Z., \& Ouyang, Z. (2017). Multi-port isolated LLC resonant converter for distributed energy generation with energy storage. In Proceedings of 2017 IEEE Energy Conversion Congress and Exposition (ECCE) (pp. 2219-2226). IEEE. https://doi.org/10.1109/ECCE.2017.8096434

\section{General rights}

Copyright and moral rights for the publications made accessible in the public portal are retained by the authors and/or other copyright owners and it is a condition of accessing publications that users recognise and abide by the legal requirements associated with these rights.

- Users may download and print one copy of any publication from the public portal for the purpose of private study or research.

- You may not further distribute the material or use it for any profit-making activity or commercial gain

- You may freely distribute the URL identifying the publication in the public portal 


\title{
Multi-Port Isolated LLC Resonant Converter for Distributed Energy Generation with Energy Storage
}

\author{
Kevin Tomas-Manez, Zhe Zhang and Ziwei Ouyang \\ Department of Electrical Engineering \\ Technical University of Denmark \\ Email: ktma@elektro.dtu.dk
}

\begin{abstract}
Distributed energy generation systems with energy storage and microgrids have attracted increasing research interest in recent years. Therefore, multi-ports dc-dc converters have gained more interest. However, when integrating into multiple port converters, the power flow control and ports regulation increase in complexity. In this paper, an isolated multi-port bidirectional converter based on an LLC converter is presented. The converter operates as a dc transformer at a fixed switching frequency and duty cycle without any control loop. The resonant tanks are designed to ensure soft-switching for the whole power range and minimize the voltage variation of the unregulated ports. In order to verify the converter operation, a $1 \mathrm{~kW}$ prototype with a $600 \mathrm{~V}$ maximum voltage has been implemented.
\end{abstract}

\section{INTRODUCTION}

The future of the electricity grid is moving towards distributed energy generation systems (DGS) and microgrids. The large increase of distributed energy sources, mostly household photovoltaic (PV) systems, has allowed the small consumer to also become an electricity producer. However, the continuously growing number of small decentralized energy sources results in additional drawbacks for the grid quality due to the discontinuity of renewable energy sources. Utilization of local energy storage (LES) systems can support the electricity grid by balancing the energy production and demand. Distributed energy generation systems with LES in microgrid systems comprise a combination of different sources and loads. A typical example of such combinations can include a DGS, such as independent PV arrays; an energy storage system, such as standalone batteries and electrical vehicles; and the household load together with the electricity grid, which can operate as a source or a load.

Multi-port power converters are usually a solution to integrate multiple energy sources and loads providing the advantages of low components count, high power density and high efficiency. However, the complexity of these systems is high in terms of control and regulation of the power flow direction and magnitude. Furthermore, this complexity increases when considering the additional control features required for some sources and loads, such as maximum power point tracking (MPPT) for PV panels or charging and discharging power of batteries. Therefore, in such systems, flexibility and simplicity of multiple sources and loads interconnection should be considered a key design parameter.

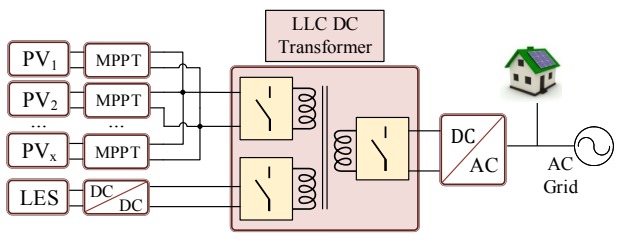

Fig. 1. Multi-port DC Transformer.

For systems with galvanic isolation an increased interest towards resonant converters has arisen, due to their advantages in reduced switching losses for wide power ranges. Resonant converters are composed by a switching bridge generating a voltage pulse which excites a resonant tank, creating a sinusoidal current at the primary side circuit. This sinusoidal current is transferred and scaled to the secondary side rectifier bridge and filtered by the output capacitance. Therefore, due to the sinusoidal current, the switches may achieve Zero Voltage Switching (ZVS) and Zero Current Switching (ZCS).

Up to date, investigations related to soft-switched multiport power converters to integrate DGS with energy storage and grid-connected inverters can be found. Authors in [1] and [2] presented three-port converters (TPC) derived from the Dual-Active Bridge (DAB), where each port is controlled throughout phase-shift modulation and duty cycle control is employed to extend the ZVS operating range. In [3] authors proposed a four-port quad-active-bridge (QAB) also derived from the $\mathrm{DAB}$, where each port is controled with phaseshift modulation. However, the DAB topology present some limitations on soft-switching operation for the entire power range. In this regard, the LLC resonant converter presents some advantages since it allows soft-switching operation from light-load to heavy load. Authors in [4] and [5] presented an isolated TPC with two LLC resonant tanks. Phase-shift between each port is used to control power flow while softswitching operation is obtained in all switches for wide power ranges. Authors in [6] and [7] proposed different topologies derived from the LLC converter, where up to two renewable energy sources and an energy storage system are connected to the same port while the load remains at the secondary side. Such topologies allow ZVS as well as a reduced components count.

All the solutions cited above present some drawbacks in 


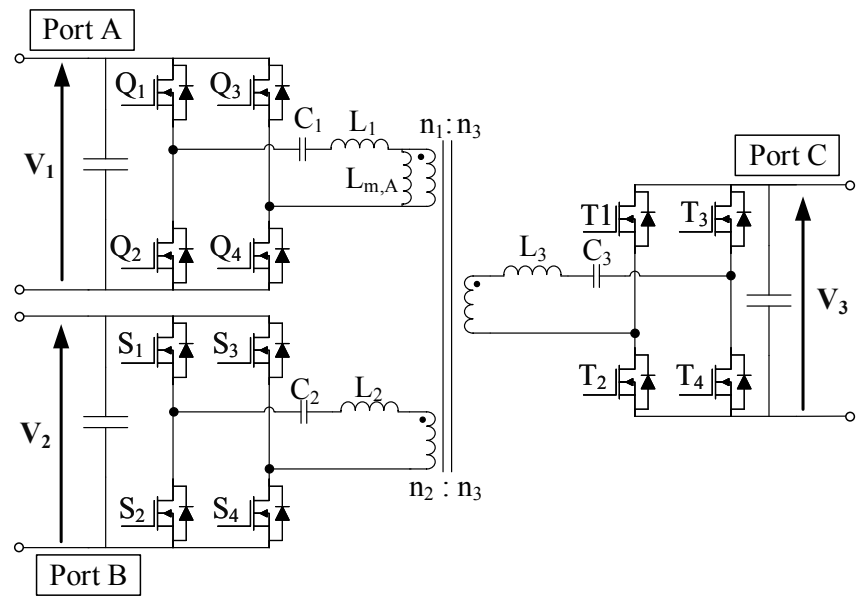

Fig. 2. Topology of the multi-port LLC converter.

terms of modularity, since they do not allow the interconnection of more sources and loads with independent control. Authors in [8] proposed the utilization of a TPC LLC converter as a dc transformer which generates three dc buses at different voltage levels to accommodate sources and loads with different voltage ratings. Experimental results from [8] demonstrate that due to the inherent cross and load regulation of the LLC converter, the voltage variation at each port is relatively small for the entire power range. This allows the operation of the system in open-loop at a fixed switching frequency and duty cycle.

This paper proposes the utilization of a TPC operating as a dc transformer with a distributed LLC resonant tank to interconnect PV arrays with independent MPPT, an energy storage system and a grid connected inverter for household applications. As shown in Fig.1, the proposed topology eases modularity and simplicity of interconnection, since multiple sources can be connected to a single port without interfering with the operation of the dc transformer. In this paper the operating principle of the LLC as a dc transformer is analysed. A design methodology which aims to reduce the voltage variation across each port and ensure soft-switching operation in all switches for the whole power range is given.

\section{TOPOLOGY AND OPERATING PRINCIPLE}

The proposed converter is shown in Fig.2. The power converter is based on a LLC topology with H-bridge cells. The converter is utilized to provide isolation between ports and setting the voltage gain from port to port. The converter is operated in open-loop at a fixed switching frequency and at $50 \%$ duty cycle. Ports that are operating as sources are actively switched, while ports operating as load are turned off and the body diodes are used as a passive rectifier bridge. Since the bi-directionality of the converter requires certain symmetry, the resonant network is distributed among the three ports. Each resonant tank is composed by a capacitor $C_{r}$ and an inductor $L_{r}$, which is the sum of an external inductor and the transformer leakage inductance.
For the proposed converter, port A is used as a unidirectional port for PV panels. Each PV string can have independent MPPT by using external dc/dc converters. Port B is a bidirectional port used for local energy storage which can be composed, for example, by a combination of batteries and supercapacitors. Each energy storage system can be independently regulated using external $\mathrm{dc} / \mathrm{dc}$ converters. Using external dc-dc converters to control each source or energy storage element not only allows a simplified and decoupled control system, but also allows an optimized design for each unit and modularity (i.e. more units can be added to each port without interfering with the system performance). Finally, port $\mathrm{C}$ is a bidirectional port connected to the DC bus and the gridtied inverter.

The grid-tied inverter regulates the DC bus to a suitable voltage level, usually $400 \mathrm{~V}$, therefore the voltage across port C $V_{3}$ can be considered constant. Then, due to the inherent cross and load regulation characteristics of the converter [8], the voltage across the other two ports can be self-cross and load regulated using the transformer turns ratio and the dc gain characteristics of the resonant tank.

Treating all ports as identical, three operation modes can be distinguished:

1) Single-input single-output (SISO): In this mode one of the ports is operating as a source and port $\mathrm{B}$ or $\mathrm{C}$ as a load. The remaining port is not operating. The input port is actively switched with $50 \%$ duty cycle while the switches of the output port are turned off, therefore the output bridge operates as a passive rectifier.

2) Single-input dual-output (SIDO): In this mode the PV port (i.e. port A) operates as source and the other two ports as loads. The PV port is actively switched with $50 \%$ duty cycle and the output ports are switched off.

3) Dual-input single-output (DISO): In this mode Port A and one of the other two ports operate as a source, while the remaining port operates as a load. The switching cells of the input ports are actively switched with $50 \%$ duty cycle and the output bridge acts a passive rectifier. In this operation mode a special attention in the design has to be made. The switches gate signals have to be synchronized, otherwise a phase-shift might be introduced between the input ports, modifying the converter operating principle.

\section{A. LLC converter operating principle}

In Fig.3 the AC equivalent circuit for the resonant tank in SIDO operation is shown. The input voltage of a resonant tank $v_{r 1}(t)$, is a square waveform at the switching frequency $w_{s w}$ changing from $-V_{1}$ to $V_{1}$ due to the full-bridge topology. When operating in the vicinity of the resonance frequency, the output voltage and current of a resonant network can be well approximated using the First Harmonic Approximation (FHA) from the Fourier series as shown in (1) and (2).

$$
\begin{aligned}
& v_{r i}(t)=\frac{4 V_{i}}{\pi} \cdot \sin \left(w_{s w} t-\phi_{v}\right) \\
& i_{r i}(t)=\frac{\pi I r_{i}}{2} \cdot \sin \left(w_{s w} t-\phi_{i}\right)
\end{aligned}
$$




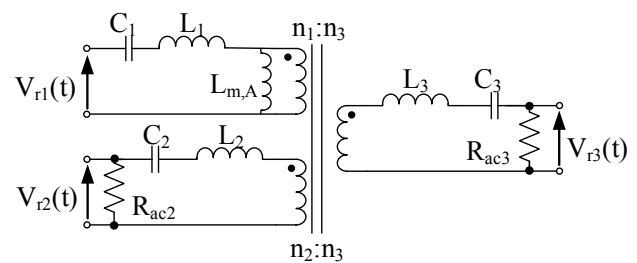

Fig. 3. AC equivalent circuit in SIDO operation.

Where $i=2,3, V_{i}$ refers to the amplitude of output square wave voltage, $i_{r i}$ refers to the fundamental component of the current at the output resonant tanks and $I r_{i}$ refers to the rms value.

Since $v_{r i}(t)$ and $i_{r i}(t)$ are in phase $\phi_{v}=\phi_{i}$, the equivalent dc load $R_{a c}$ of the resonant network can be modelled as the ratio of instantaneous voltage and current, given by (6).

$$
R_{a c}=\frac{8 R_{L}}{\pi^{2}}
$$

Where $R_{L}$ is the load at the output ports.

The resonance frequency of a resonant tank composed by $C_{r}$ and $L_{r}$ is given in (4).

$$
\omega_{r}=\frac{1}{\sqrt{L_{r} C_{r}}}
$$

Typical voltage gain curves of the resonant in terms of normalized frequency $\left(\omega_{n}=\omega_{s w} / \omega_{r}\right)$ are shown in Fig.4. When the converter operates with an inductive impedance (i.e. negative gain slope at the switching frequency) [9], the current flowing through the resonant tank lags the voltage which allows ZVS turn on of the switches at the input ports. In addition, when the converter operates at $w_{n} \leqslant 1$, the sinusoidal output current becomes zero before the switching occurs. This allows ZCS turn off of the output rectifiers. Note that for lower switching frequency with respect to the resonance frequency, the circulating current at the input bridges increases.

As can be seen in Fig.4, when the output power increases the dc characteristic changes and the resonant tank impedance might become capacitive, being the gain slope positive at the switching frequency and thus, ZVS would be hindered. Therefore, the resonant tank has to be carefully designed in order to have an inductive impedance for the entire power load.

\section{B. Resonant tank design considerations}

In practice, the conventional LLC converter is designed to have line and load regulation throughout frequency modulation. To perform these regulations, the resonant tank should satisfy certain gain requirements given by the converter power load and voltage ratings. However, the design approach of a multi-port LLC converter operating as a dc transformer with self-cross and load regulation, differs from the conventional approach.

In this design approach the gain of the resonant tank is chosen to be close to the unity gain for the entire power range,

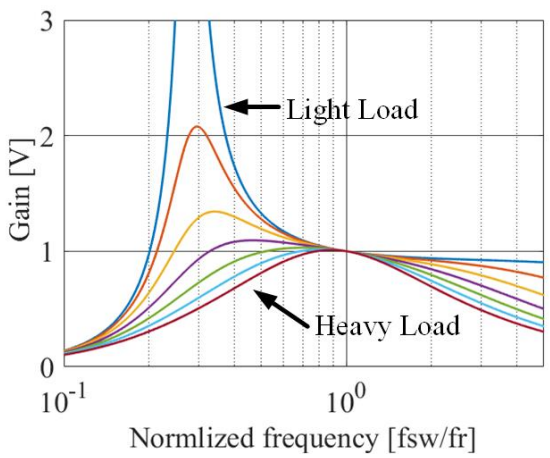

Fig. 4. Typical DC gain of a LLC resonant tank for different power ratings or Q factors.

since it is and the transformer turns ratio is selected to match the required voltage gain, as shown in (5), to obtain the desired ports voltage. Referring to Fig.4, one can observe that the unity gain of the resonant tank is found at the vicinity of the resonance frequency. Therefore, in order to ensure softswitching operation and keep a low circulating current, the switching frequency is chosen below but close to the resonance frequency.

$$
\frac{V_{1}}{V_{2}}=n_{1: 2} \quad \frac{V_{1}}{V_{3}}=n_{1: 3}
$$

Design of the resonant components such as $L_{i}, C_{i}$ and $L_{m}$ should consider maximum power load, voltage gain variation, circulating energy in the resonant tanks and soft-switching conditions. The selection of the resonant components are important for power conversion efficiency and improving the self-cross and load regulation. Inductance ratio $k$ and quality factor $Q$ are key design parameters of the LLC converter, since they will determine the dc gain characteristics and available power range.

The quality factor $Q$ is determined by the resonant tank characteristic impedance $Z_{r}$ and the power load as shown in (6). $Q$ has an impact on the gain characteristics and available power range. With an increasing $Q$ factor, dc voltage gain decreases and the gain peak value moves towards the resonant frequency. However, if the $Q$ factor is too high, the dc gain can be decreased lower than the unity gain and the gain slope before the resonance frequency becomes positive. Then, the input impedance of the resonant tank becomes capacitive below resonance, which hinders soft-switching operation. On the other hand, if the $Q$ factor is too low, the low characteristic impedance of the resonant tank will affect the converter efficiency due to the increased circulating current. To exemplify the effect of $Q$, Fig.4 shows dc gain of a resonant tank for different $Q$ factors.

$$
\begin{gathered}
Q=\frac{Z_{r}}{R_{a c}} \\
Z_{r}=\sqrt{\frac{L_{r}}{C_{r}}}=\omega_{r} L_{r}=\frac{1}{\omega_{r} C_{r}}
\end{gathered}
$$


Therefore, for a fixed switching frequency, there is a maximum quality factor $Q_{\max }$ which has to be determined to properly size the resonant tank and thus, fulfil the load requirements. Determining $Q_{\max }$ has been already addressed in many publications, in this design the $\mathrm{k}-\mathrm{Q}$ criterion derived in [9] has been considered. According to the k-Q analysis, the condition given in (8) has to be fulfilled in order to ensure the operation in the inductive region.

$$
R_{a c} \geqslant \sqrt{\frac{L_{m}}{C_{e q}}}
$$

Where $C_{e q}$ is the equivalent capacitance of the resonant capacitors distributed among the three different ports (i.e. $C_{1}$, $C_{2}$ and $C_{3}$ ).

Combining (8) with (7) the maximum equivalent characteristic impedance of the resonant tank $Z_{r e q, \max }$ is given by (9).

$$
Z_{r e q, \max }=\frac{R_{a c, \min }^{2}}{\omega_{r} L_{m}}
$$

Where $R_{a c, \text { min }}$ is the equivalent load at the rated power of the converter.

Combining (9) with (7), the maximum equivalent inductance of the resonant network $L_{r, \max }$ can be calculated as shown in (10).

$$
L_{r, \max }=\frac{R_{a c, \min }^{2}}{\omega_{r}^{2} L_{m}}
$$

For the proposed three port LLC converter, the equivalent inductance seen from port A $L_{e q, A}$ is calculated as shown in (11).

$$
L_{e q, A}=L_{1}+\left(\frac{1}{n_{1: 2}^{2} L_{2}}+\frac{1}{n_{1: 3}^{2} L_{3}}\right)^{-1}
$$

Then, from (8), the resonant tank design has to ensure (12).

$$
L_{r, \max } \geqslant L_{e q, A}
$$

The other design parameter is the inductance ratio $k$. The inductance ratio $k$ affects the load regulation and softswitching conditions [9]. If $k$ is high, the voltage gain in the vicinity of the resonance frequency is very close to the unity gain and the gain variation for different loads will be small [9]. Conversely, with low $k$ ratios, the converter will have a poor self-cross and load regulation characteristic and the ports voltage will significantly change from their rated values. For a LLC converter with a distributed resonant tank, the $k$ ratio is given by (13).

$$
k=\frac{L_{m, A}}{L_{e q, A}}
$$

\section{Magnetizing inductance selection}

To ensure ZVS of the switches at the input ports, the output capacitances of the MOSFETs have to be fully charged or discharged during the dead-time period. Therefore a minimum magnetizing current given by (14), is required [10].

$$
I_{m}>\frac{2 C_{o s s} V}{t_{d}}
$$

Assuming that the resonant tank operates at the unity gain, the maximum magnetizing inductance $L_{m}$ required to achieve ZVS can be calculated with (15) according to [10].

$$
L_{m} \leqslant \frac{t_{d}}{8 C_{o s s} f_{s w}}
$$

\section{Transformer design considerations}

The leakage inductances of the transformer form part of the distributed resonant tank, affecting the performance of the converter. The resonance frequency of the resonant tank including the leakage inductance is shown in (16). The leakage inductance of a transformer depends on the coupling factor, which at the same time depends on the winding geometry. Depending on the operation mode in which the converter is operating (i.e. SISO, DISO or SISO) and the active or inactive ports, the coupling factor changes and thereby, also the transformer leakage inductance.

$$
\omega_{r, l k}=\frac{1}{\sqrt{\left(L_{r}+L_{l k}\right) C_{r}}}
$$

According to (16), with an increasing leakage inductance, the resonance frequency of the resonance tank decreases. Therefore, if the leakage inductance is not taken into account, the converter might enter into the operation above the resonance frequency due to the fixed switching frequency. As a consequence, ZCS operation at the output rectifiers might be lost. For a given transformer, the worst-case leakage inductance or coupling factor has to be used to set the switching frequency to at least $\omega_{r, l k}$.

\section{DESIGN EXAMPLE}

Fig.5 shows the flowchart to design the resonant network and selecting the appropriate switching frequency. Below a design example is given to illustrate the design procedure. Table I shows the specifications of the converter and table II shows the selected parameters.

To match the gain requirements the turns ratio chosen according to (5) is $n_{1-2}=1.5$ and $n_{1-2}=3$. For the output capacitance $C_{\text {oss }}$ of the selected MOSFETS and a dead-time of $200 \mathrm{~ns}$, the magnetizing inductance $L_{m, A}$ is set to $560 \mu \mathrm{H}$. Then, according to (10), the maximum equivalent resonant tank inductance referred to port A $L_{r A, \max }$ which allows ZVS is found to be $170 \mu \mathrm{H}$. The inductance ratio $k$ is set to 6 , which results in a $L_{r A}$ lower than $L_{r A, \max }$. Then, the resonant inductors $L_{2}$ and $L_{3}$ are set to $28 \mu \mathrm{H}$ and $7 \mu \mathrm{H}$ respectively. According to (11), the resonant inductor $L_{1}$ is calculated resulting in $62 \mu \mathrm{H}$. Finally, the resonant capacitors of each port 


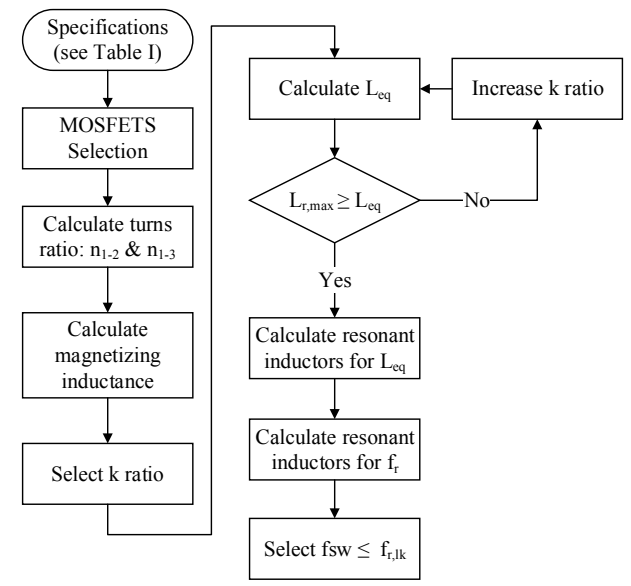

Fig. 5. Optimal design flowchart.

TABLE I

SPECIFICATIONS

\begin{tabular}{l|lllll}
\hline Parameter & $V_{1}$ & $V_{2}$ & $V_{3}$ & $P_{\max }$ & $f_{r}$ \\
Value & $600 \mathrm{~V}$ & $200 \mathrm{~V}$ & $400 \mathrm{~V}$ & $1 \mathrm{~kW}$ & $150 \mathrm{kHz}$ \\
\hline
\end{tabular}

TABLE II

DESIGN PARAMETERS

\begin{tabular}{l|lllll}
\hline Parameter & $n_{1-2}$ & $n_{1-3}$ & $t_{\text {dead }}$ & $C_{\text {oss }}$ & $L_{m, A}$ \\
Value & 3 & 1.5 & $200 \mathrm{~ns}$ & $300 \mathrm{pF}$ & $560 \mu \mathrm{H}$ \\
\hline Parameter & $L_{1}$ & $L_{2}$ & $L_{3}$ & $L_{l k 1, \max }$ & $C_{1}$ \\
Value & $62 \mu \mathrm{H}$ & $28 \mu \mathrm{H}$ & $7 \mu \mathrm{H}$ & $2 \mu \mathrm{H}$ & $18 \mathrm{nF}$ \\
\hline Parameter & $C_{2}$ & $C_{3}$ & $f_{r, l k}$ & $f_{s w}$ & \\
Value & $40 \mathrm{pF}$ & $160 \mathrm{pF}$ & $147 \mathrm{kHz}$ & $145 \mathrm{kHz}$ & \\
\hline
\end{tabular}

are calculated using (4) for the resonance frequency given in table I.

The transformer leakage inductance is measured under all operation modes (i.e. SISO, SIDO and DISO) using an impedance analyzer. The largest leakage inductance occurs between windings of port $\mathrm{A}$ and port $\mathrm{C}$ when port $\mathrm{B}$ is left opened $\left(L_{l k, 13}\right)$, being $2 \mu \mathrm{H}$. This results in a resonant frequency of approximately $147 \mathrm{kHz}$ according to (16). Then, the switching frequency is set to $145 \mathrm{kHz}$ to allow some margin.

In order to illustrate the effect of the inductance ratio on the converter load regulation characteristics a second design with $k=3$ have been performed following the procedure aforementioned. Then, with the resulting parameters, the ac equivalent circuit of the converter as shown in Fig. 3 has been analyzed with AC simulations using SPICE software. Fig.6 shows the dc gain obtained for both designs at heavy load, mid load and light load. In order to solely visualize the gain of the distributed resonant tank, the dc gain obtained is multiplied by the transformer turns ratio. According to the results obtained, the total voltage variation from light load to heavy load for $k=3$ is $1.1 \%$ while with $k=6$ is $0.03 \%$. Therefore, with a high $\mathrm{k}$ ratio the load regulation characteristic of the converter is improved.

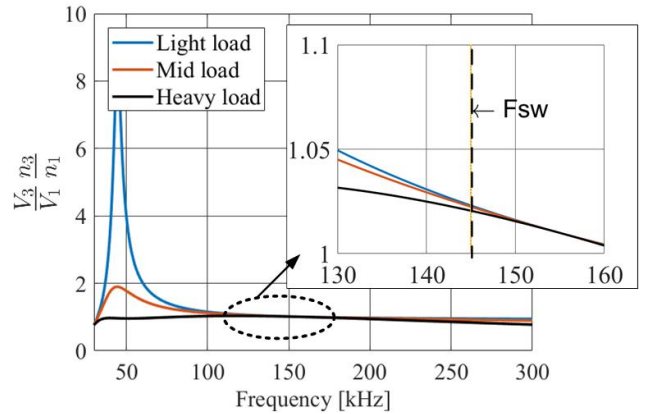

(a) $\mathrm{k}=6$

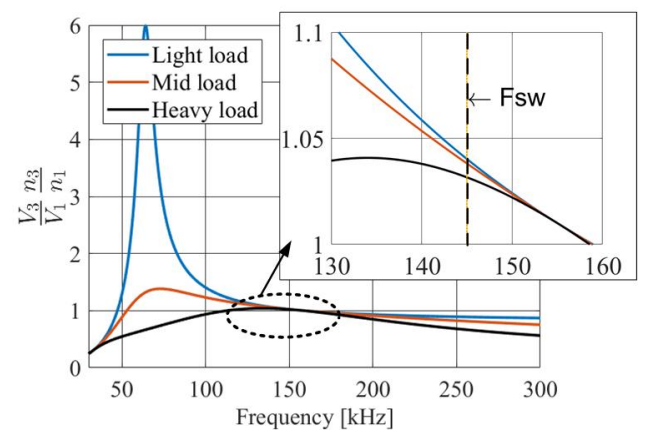

(b) $\mathrm{k}=3$

Fig. 6. DC gain of the distributed resonant tank for different inductance ratios.

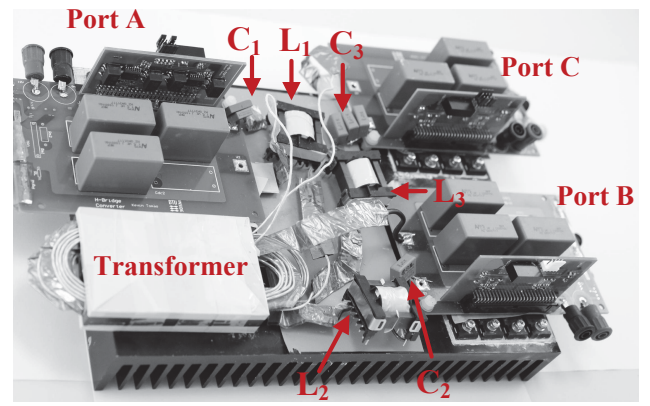

Fig. 7. Prototype of the multi-port LLC converter.

\section{EXPERIMENTAL RESULTS}

The operation of the proposed converter is analysed on a prototype with the specifications given in Table I and the parameters given in Table II. Fig.7 shows a picture of the prototype.

The converter has been tested under the three operation modes as follows:

1) SIDO: Port A operating as a source while ports $\mathrm{B}$ and $\mathrm{C}$ operate as loads. Voltage across port C (i.e. grid-side port) is kept constant at $400 \mathrm{~V}$.

2) DISO: Ports $\mathrm{A}$ and $\mathrm{C}$ operate as source while port $\mathrm{B}$ operates as a load. Port $\mathrm{C}$ is supplied by a voltage source at a constant voltage of $400 \mathrm{~V}$ and port $\mathrm{A}$ is supplied by a voltage source in constant current operation. The output current of the voltage source is manually modified to achieve different power sharing among the input ports. 


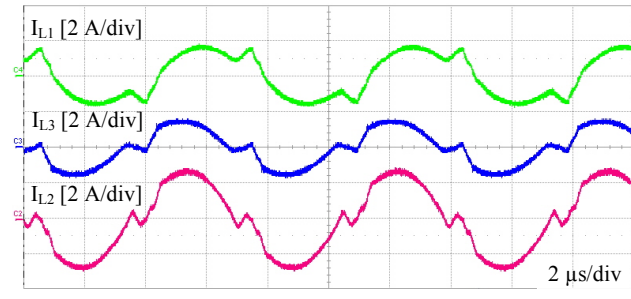

(a) SIDO

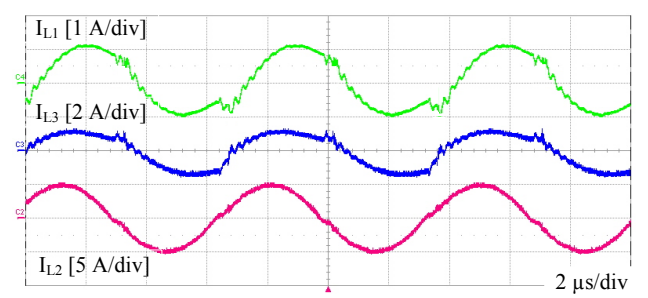

(b) DISO

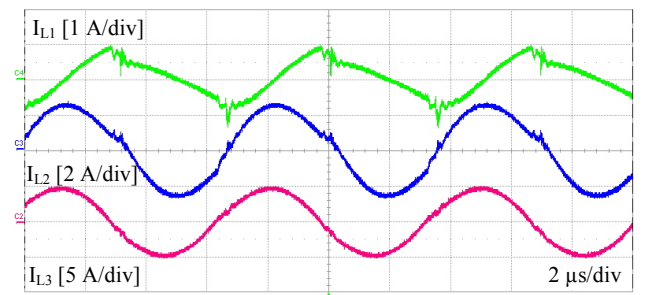

(c) SISO (Port A off)

Fig. 8. Tranformer currents at $65 \%$ rated load on different operation modes.

3) SISO: Port C operates as a source, port B as a load and port $\mathrm{A}$ remains unloaded. Port $\mathrm{C}$ is supplied with a voltage source at constant voltage.

\section{A. Steady-state waveforms}

Fig. 8 shows the experimental waveforms of the prototype at $65 \%$ rated load under all operation modes. The figure illustrates the current flowing through the resonant tanks. In Fig. $8 \mathrm{a}$ and $8 \mathrm{~b}$ the currents at the input and output ports are nearly sinusoidal due to the operation near the resonant frequency determined by the resonant tanks. Therefore, the resonant frequency of the distributed resonant tanks have a good match. In Fig.8c, the current through the resonant tank of port A $I_{L 1}$ looks like a triangular wave because the port is unloaded, being the only load the capacitor across $V_{1}$. The current $I_{L 1}$ is then, the magnetizing current.

Fig.9 illustrates the ZVS operation under SIDO at different power levels. This refers to the worst-case condition for ZVS operation, since port $\mathrm{A}$ has the larger voltage rating and the lowest circulating current. Referring to (14), one can see that to achieve ZVS operation for a given MOSFET, larger voltages and lower currents will hinder ZVS operation. Fig.9 illustrates the current flowing through the resonant tank, the drain-source voltage and the gate-source voltage of $Q_{2}$ at $10 \%, 65 \%$ and $100 \%$ rated load. The waveforms show that in all conditions $\mathrm{ZVS}$ is achieved, which is not dependent on the load.

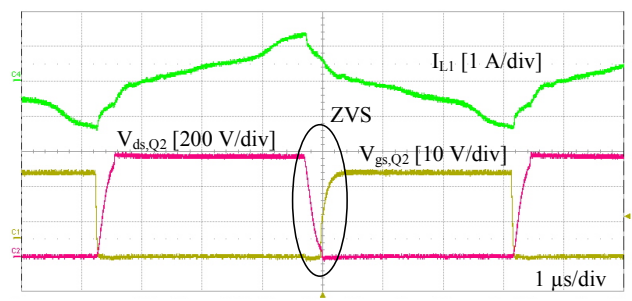

(a) $10 \%$ Load

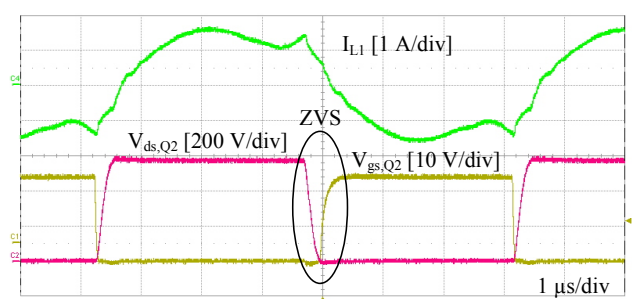

(b) $65 \% \mathrm{Load}$

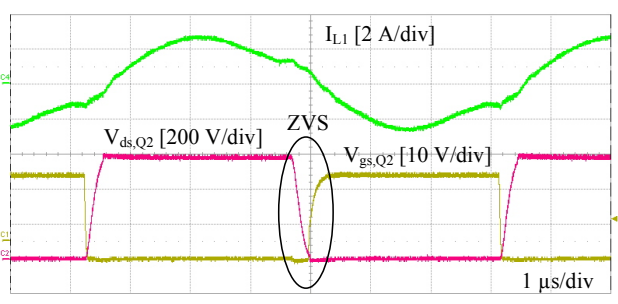

(c) $100 \%$ Load

Fig. 9. ZVS waveforms of Port A under SIDO operation mode at different rated loads.

Fig.10 and 11 show the waveforms of the output bridge in SIDO and DISO operation modes at different power levels to verify the ZCS operation. Fig.10a shows the resonant tank current of port B, the drain-source voltage and gate-source voltage of $S_{4}$ while Fig.10b shows the resonant tank current of port $\mathrm{C}$, the drain-source voltage and gate-source voltage of $T_{4}$. The converter is operating in SIDO mode at $65 \%$ rated load, which is equally shared among the output ports. At medium-low power rating ZCS turn-off is successfully achieved, while the turn-on is performed at lower current due to the sinusoidal shape of the current. A high frequency ringing can be observed during the dead-time due to the resonance between the parasitic capacitances and the resonant inductor in series with the leakage inductance. Fig.11 shows the ZCS operation of port B at DISO operation at $40 \%$ and $100 \%$ load. This refers to the worst-case scenario to achieve ZCS, as it is the higher current port, and therefore the sinusoidal current requires of larger time to reach zero. ZCS switching, differently from ZVS, depends on the load conditions. At full load condition, shown in Fig.11b, all switches turn off with ZCS.

\section{B. Dynamics}

In order to observe the dynamics of the system, transitions between SISO and DISO operation have been analyzed by enabling and disabling port A during DISO operation. Fig. 


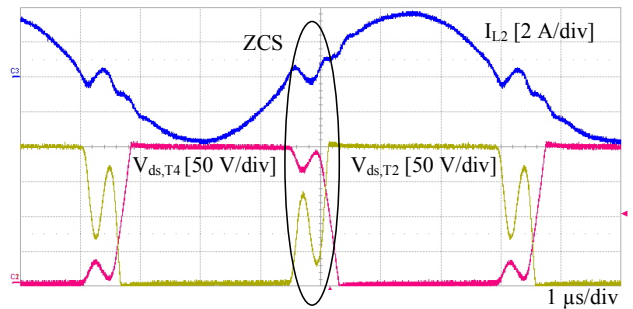

(a) Port B

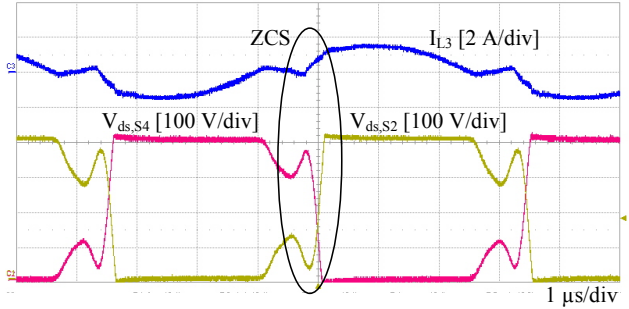

(b) Port C

Fig. 10. ZCS waveforms under SIDO operation at $65 \%$ rated load with equal load sharing among output ports.

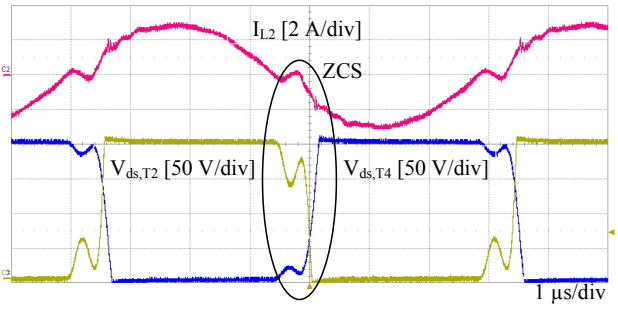

(a) $40 \%$ rated load

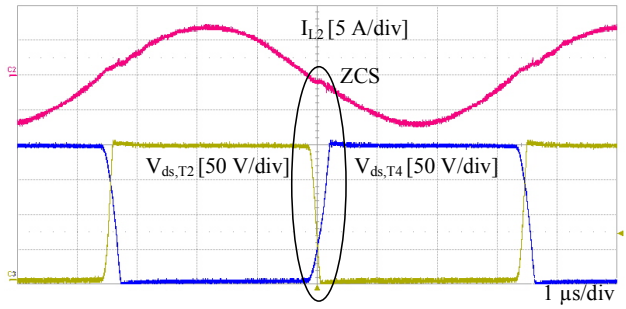

(b) Rated load

Fig. 11. Port B ZCS waveforms under DISO operation.

12a shows the transition from DISO and SISO when port A is switched off and Fig.12b shows the transition from SISO to DISO when port $\mathrm{A}$ is switched on. Port $\mathrm{C}$ operates as an input while port $\mathrm{B}$ as an output. Fig. 12 illustrates the currents flowing through the input of ports $\mathrm{A}\left(I_{1}\right)$ and $\mathrm{C}\left(I_{3}\right)$, and the voltage across ports $\mathrm{A}\left(V_{1}\right)$ and $\mathrm{B}\left(V_{2}\right)$. As shown in Fig.12a, when port $\mathrm{A}$ is shut down, $I_{1}$ gradually decreases to zero and and $I_{3}$ increases with the same rate. Voltages across the self-regulated ports $V_{1}$ and $V_{2}$ are stable during the power transition. Switching on dynamics does not differ from the switching off.

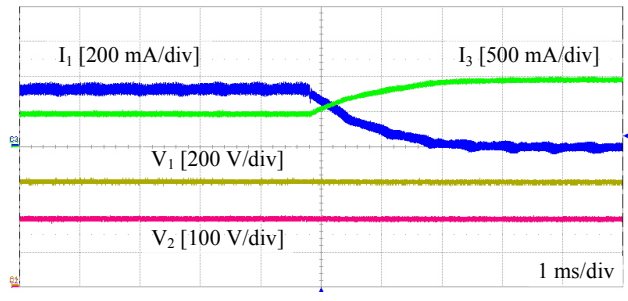

(a) DISO to SISO disconnecting Port A

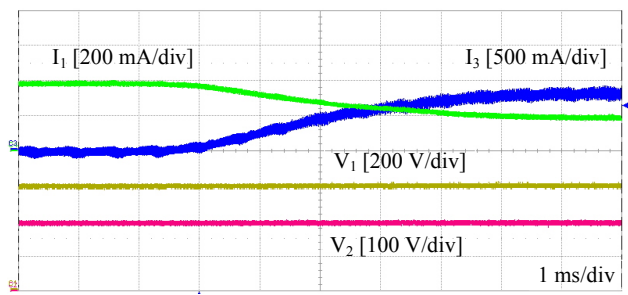

(b) SISO to DISO disconnecting Port A

Fig. 12. Operation modes transition.

\section{Self-cross and load regulation}

The steady state voltage regulation performance of the transformer is illustrated in Fig.13a, 13b and 13c for SIDO, DISO and SISO operation modes respectively. Fig. 13 shows the voltage in p.u. values, being the base voltage the rated voltage at each port. From light load to full load, the maximum voltage variation across port $\mathrm{A}$ is found to be $2.5 \%$. The worst-case steady state regulation for port $\mathrm{A}$ is observed in SIDO operation, where port A is the only sourcing port. The maximum voltage variation across port $\mathrm{B}$ occurs in SISO operation being $5.6 \%$, which coincides with the worst-case scenario. In SISO, the output impedance of the converter is higher compared to the other operation modes [8], and therefore a worst steady state voltage regulation is expected.

\section{Efficiency}

Efficiency results for all operation modes are shown in Fig.14. To obtain consistent efficiency measurements, in dualoutput and dual-input modes, the power sharing between output loads and input sources respectively has been kept nearly constant at a $50 \%$ share.

Highest efficiency is found at medium to full load in DISO operation mode, reaching a peak efficiency of $95.9 \%$ at full load. SISO operation mode shows the worst efficiency because port A does not participate in the active power transfer, but it does in the circulating power as can be seen in Fig.8c. Therefore, even though the unloaded port does not carry active power, conduction losses at the switches and losses in the resonant tank are still present up to some extent.

As previously mentioned, switches of the output ports are used as a passive rectifier by using the MOSFET body diodes. The switches selected for this prototype are SiC MOSFETS, which have a high voltage drop across the body diode during reverse conduction (it can be found to be approximately $2 \mathrm{~V}$ ). This leads to increased conduction losses at the output ports. In order to highly increase the efficiency, Si MOSFETS with 


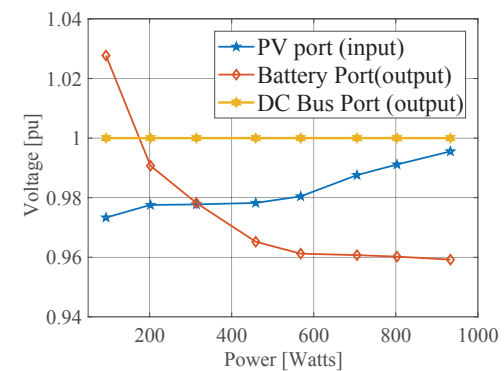

(a) SIDO. Output ports with equal power sharing

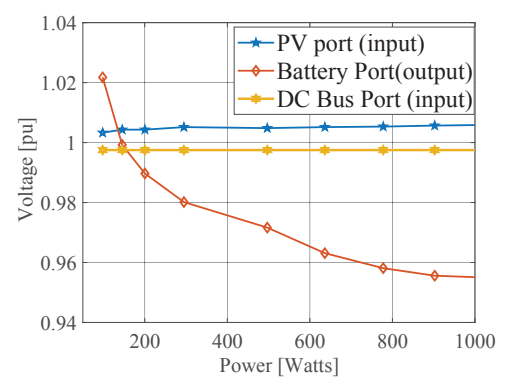

(b) DISO. Inputs ports with equal power sharing

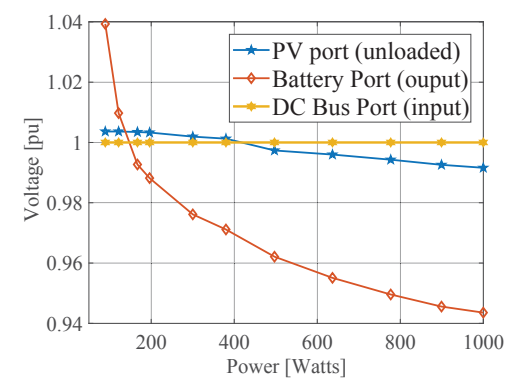

(c) SISO.

Fig. 13. Steady-state voltage regulation.

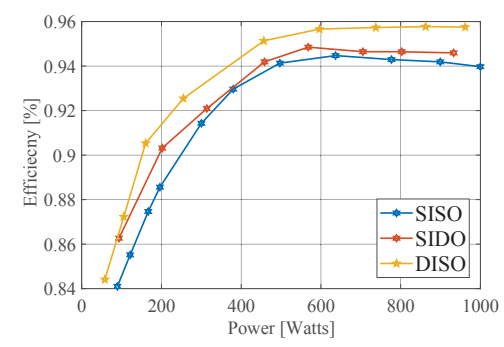

Fig. 14. Efficiency measurements.

a low voltage drop in reverse conduction might be selected or Schottky diodes in parallel with the MOSFETS can be used.

\section{CONClusion}

In this paper an isolated TPC LLC converter operating as a dc transformer has been presented. The converter aims to simplify the integration of multiple PV arrays with independent MPPT together with an energy storage system and a grid- connected inverter. The converter operates with open-loop, at a fixed switching frequency and duty cycle. Due to the benefits of the LLC converter in terms of self-cross and load regulation, when the voltage across one of the ports is fixed, as the DC bus connected to the grid-tied inverter, the voltage across the other ports can be adjusted with the transformer turns ratio. Due to the operation at a fixed switching frequency, ZVS at the input ports and ZCS at the output ports can be easily obtained for the entire power range. A detailed design procedure has been presented in order to ensure soft-switching operation and improve the cross and load regulation characteristics. The proposed solution has been verified on a $1 \mathrm{~kW}$ prototype. Results show that, due to the voltage regulation characteristics of the converter, voltage variation across each port can be kept relatively low. Soft-switching operation is obtained under all operating conditions and thus, achieving efficiencies up to $95.9 \%$. Efficiency could be further improved by selecting MOSFET with low voltage drop in reverse conduction mode, in order to reduce the losses when acting as a passive rectifier.

\section{REFERENCES}

[1] H. Tao, A. Kotsopoulos, J.L. Duarte and A.M. Hendrix, TransformerCoupled Multiport ZVS Bidirectional DCDC ConverterWithWide Input Range, IEEE, Transaction on power electronics, Vol. 22, No. 2, pp. 771-781, March 2008.

[2] C. Zhao, S.D. Round and J.W. Kolar, An Isolated Three-Port Bidirectional DC-DC ConverterWith Decoupled Power Flow Management, IEEE, Transaction on power electronics, Vol. 23, No. 5, pp. 2443-2453, September 2008

[3] S. Falcones, R. Ayyanar and X. Mao, A DCDC Multiport-ConverterBased Solid-State Transformer Integrating Distributed Generation and Storage, IEEE, Transaction on power electronics, Vol. 28, No. 5, pp. 2192-2203, May 2015.

[4] H. Krishnaswami and N. Mohan, Constant Switching Frequency Series Resonant Three-port Bi-directional DC-DC Converter, IEEE, IEEE Power Electronics Specialists Conference (PESC), June 2008.

[5] H. Krishnaswami and N. Mohan, Three-Port Series-Resonant DCDC Converter to Interface Renewable Energy Sources With Bidirectional Load and Energy Storage Ports, IEEE, Transaction on power electronics, Vol. 24, No. 10, pp. 2289-2297, October 2009.

[6] H. Wu, P. Xu, Z. Zhou and Y. Xing, Multiport Converters Based on Integration of Full-Bridge and Bidirectional DCDC Topologies for Renewable Generation Systems, IEEE, Transaction on industrial electronics, Vol. 61, No.2, pp. 856-869, February 2014.

[7] J. Zeng, W. Qiao and L. Qu, An Isolated Three-Port Bidirectional DCDC Converter for Photovoltaic Systems With Energy Storage, IEEE, Transaction on industry applications, Vol. 51, No.4, pp. 3493-3503, July/August 2015.

[8] Z. Pavlovic, J.A. Oliver, P. Alou, O. Garcia and J.A. Cobos, Bidirectional multiple port $d c / d c$ transformer based on a series resonant converter, IEEE, Applied Power Electronics Conference (APEC), 2013, pp.10751082.

[9] Il-Oun Lee and Gun-Woo Moon, The $k$-Q Analysis for an LLC Series Resonant Converter, IEEE, Transaction on power electronics, Vol. 61, No. 2, pp. 856-869, year 2014.

[10] U. Kundu, K. Yenduri and P. Sensarma, Accurate ZVS Analysis for Magnetic Design and Efficiency Improvement of Full-Bridge LLC Resonant Converter, IEEE, Transaction on power electronics, Vol. 32, No. 3, pp. 1703-1706, March 2017. 